\title{
CONF-970503--16 DOE/ER/40150--1/25 JLAB-ACC-97-08 DEVELOPMENT OF DIGITAL FEEDBACK SYSTEMS FOR BEAM POSITION AND ENERGY AT THE THOMAS JEFFERSON NATIONAL ACCELERATOR FACILITY
}

\author{
J. Karn, M. Chowdhary, A. Hutton, V. Lebedev, R. Legg, P. Letta \\ H. Shoaee, W. Watson, and J, van Zeijts \\ Thomas Jefferson National Accelerator Facility \\ 12000 Jefferson Avenue, Newport News, VA 23606 USA
}

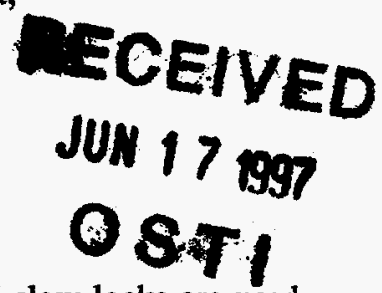

\begin{abstract}
The development of beam-based digital feedback systems for the CEBAF accelerator has gone through several stages. As the accelerator moved from commissioning to operation for the nuclear physics program, the top priority was to stabilize the beam against slow energy and position drifts $(<1 \mathrm{~Hz})$. These slow drifts were corrected using the existing accelerator monitors and actuators driven by software running on top of the EPICS control system. With slow drifts corrected, attention turned to quantifying the higher frequency disturbances on the beam and to designing the required feedback systems needed to achieve the CEBAF design stability requirements. Results from measurements showed the major components in position and energy to be at harmonics of the power line frequencies of 60,120 , and $180 \mathrm{~Hz}$. Hardware and software was installed in two locations of the accelerator as prototypes for the faster feedback systems needed. This paper gives an overview of the measured beam disturbances and the feedback systems developed.
\end{abstract}

\section{INTRODUCTION}

CEBAF is a $4 \mathrm{GeV}$ electron accelerator producing CW beams for nuclear physics research. The accelerator consists of a $45 \mathrm{MeV}$ injector and two parallel $400 \mathrm{MeV}$ linacs. The beam is recirculated through both linacs four additional times to achieve $4 \mathrm{GeV}$ of total acceleration. Multiple beams can be extracted after selected orbits and delivered to any, or each, of the three experimental halls. The ultimate stability requirements of the beam on target is $2.5 \times 10^{-5} \mathrm{rms}$ relative energy spread and maintaining an rms beam position within a $20 \mu \mathrm{m}$ window.

\section{SLOW LOCKS}

During the commissioning of the accelerator a series of slow locks were developed to stabilize the beam against slow energy and position drifts $(<1 \mathrm{~Hz})$. The locks made use of the existing beam position monitors, corrector dipoles, and SRF cavities. These monitors and actuators were controlled by a TCL/TK [1] software package running on top of the EPICS control system. A total of 15 independently controlled slow locks are used to set and maintain the orbit from the injector to the experimental halls. Three energy locks maintain the energy of the injector and each of the two linacs. Twelve orbit locks maintain the orbits in the injector, each of the nine recirculation arcs, and two of the three experimental hall transport lines. The long term relative momentum stability is typically kept to $\pm 5 \times 10^{-5}$ in the first two CEBAF arcs. Position stability is typically maintained around $\pm 100 \mu \mathrm{m}$, the resolution of the beam position monitors.

The original slow lock software has recently been upgraded to a more powerful CDEV based package [2]. The new software resolved several problems regarding CPU usage, operator friendliness, multiple lock interaction, and improved exception handling. In addition, external processes like automatic cresting of the linac RF cavities, are speeded up significantly using the new package. The result is a slow lock package that is an essential part of the long term stability of the accelerator.

\section{BEAM STABILITY MEASUREMENTS}

With slow drifts corrected, attention turned to quantifying the higher frequency disturbances. Two techniques were developed for measuring beam motion at various frequency ranges. The first method involved raising the trigger rate for the BPMs from 60 to $500 \mathrm{~Hz}$. A data acquisition routine running on the IOC local to the desired BPMs recorded 60 seconds worth of data. The buffered data was then downloaded off the IOC for analysis using MATLAB [3]. FFTs of the data produced frequency spectrums up to $250 \mathrm{~Hz}$.

\begin{tabular}{|l|r|r|r|r|c|}
\hline Location & $\begin{array}{c}\mathrm{X} \\
\mathrm{mm} .\end{array}$ & $\begin{array}{c}\mathrm{Y} \\
\mathrm{mm} .\end{array}$ & $\begin{array}{c}\mathrm{X}^{\prime} \\
\mathrm{mrad}\end{array}$ & $\begin{array}{c}\mathrm{Y}^{\prime} \\
\mathrm{mrad}\end{array}$ & $\Delta \mathrm{E} / \mathrm{E}$ \\
\hline Injector & 2.0 & 0.9 & 0.27 & 0.20 & $1.2 \times 10-3$ \\
East Arc & 0.5 & 0.2 & 0.04 & 0.08 & $0.3 \times 10-3$ \\
West Arc & 0.4 & 0.3 & 0.02 & 0.06 & $0.2 \times 10-3$ \\
\hline
\end{tabular}

Table 1: Magnitude of $60 \mathrm{~Hz}$. motion at various locations in the accelerator.

Measurements were made at key locations in the accelerator over a period of three months. The data 


\section{DISCLAIMER}

This report was prepared as an account of work sponsored by an agency of the United States Government. Neither the United States Government nor any agency thereof, nor any of their employees, make any warranty, express or implied, or assumes any legal liability or responsibility for the accuracy, completeness, or usefulness of any information, apparatus, product, or process disclosed, or represents that its use would not infringe privately owned rights. Reference herein to any specific commercial product, process, or service by trade name, trademark, manufacturer, or otherwise does not necessarily constitute or imply its endorsement, recommendation, or favoring by the United States Government or any agency thereof. The views and opinions of authors expressed herein do not necessarily state or reflect those of the United States Government or any agency thereof. 


\section{DISCLAMMER}

Portions of this document may be illegible in electronic image products. Images are produced from the best available original document. 
showed the major components in position and energy to be at harmonics of the power line frequencies of 60,120 , and $180 \mathrm{~Hz}$. The magnitude of the $60 \mathrm{~Hz}$. component at various locations in the accelerator is listed in Table 1.

The second method for measuring beam disturbances was aimed at investigating higher frequencies. This technique made use of a new design of BPMs being integrated into the accelerator. These new Switched Electrode Electronics BPMs (SEEs) are VME-based and capable of being read at up to $114 \mathrm{kHz}$ by a low level IOC routine. Data was collected at $7.1 \mathrm{kHz}$. over a 2.3 second time span [4]. A sample of this is shown in Figure 1. The amplitudes and phases of the known power line harmonics $(60,120$, and $180 \mathrm{~Hz}$.) were determined and these components were subtracted from the original signal. An FFT of the remaining signal was performed and plotted in Figure 2. This data shows the higher power line harmonics but at a much lower amplitude. An expanded plot of frequencies below $150 \mathrm{~Hz}$. is shown in Figure 3. The amplitudes of the power line harmonics are summarized in Table 2.

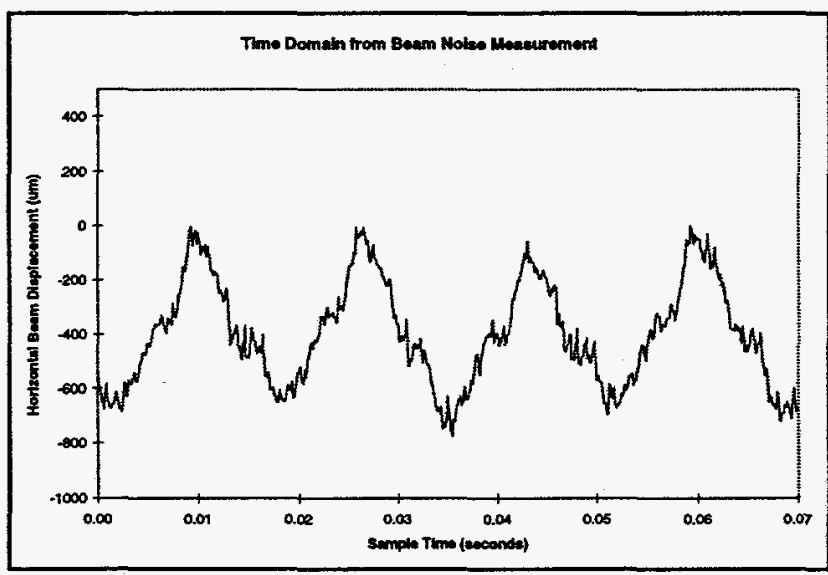

Figure 1: Horizontal beam position collected at $7.1 \mathrm{kHz}$.

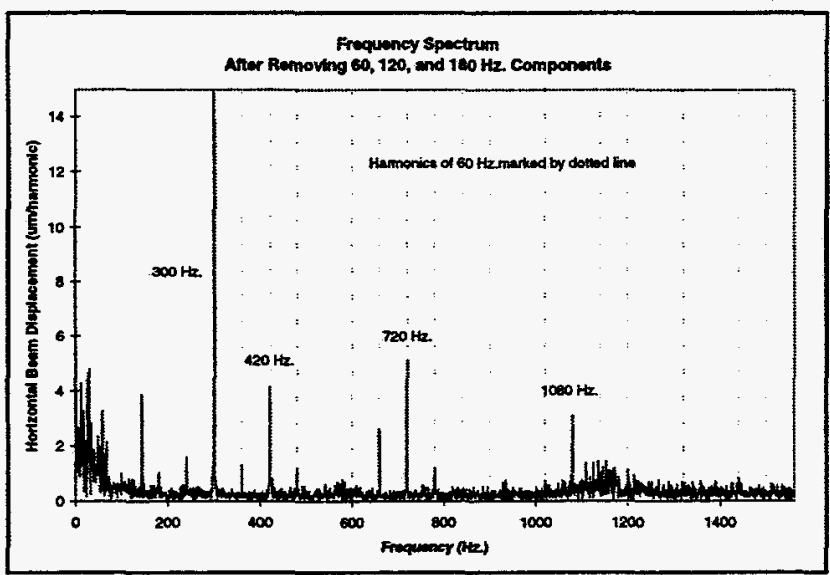

Figure 2: FFT following removal of 60,120 , and $180 \mathrm{~Hz}$. contributions.

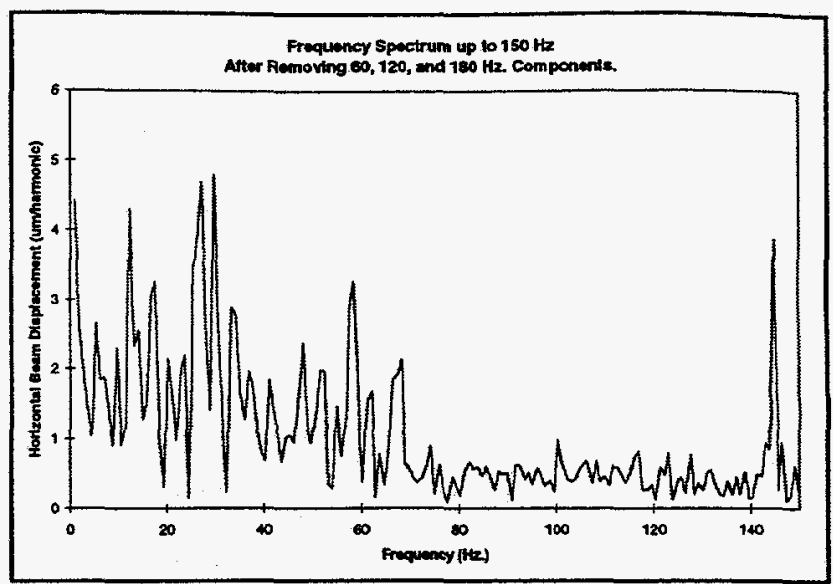

Figure 3: Expanded view of lower frequencies..

\begin{tabular}{|c|c|c|}
\hline Component & Amplitude $(\mu \mathrm{m})$ & sigma $(\mu \mathrm{m})$ \\
\hline $60 \mathrm{~Hz}$. & 246.3 & 14.7 \\
\hline $120 \mathrm{~Hz}$. & 23.5 & 1.6 \\
\hline $180 \mathrm{~Hz}$. & 54.5 & 0.8 \\
\hline $\begin{array}{c}\text { Sum of higher } \\
\text { harmonics }\end{array}$ & 25.5 & 0.6 \\
\hline
\end{tabular}

Table 2: Magnitude of power line harmonics

\section{PROTOTYPE FAST FEEDBACK SYSTEMS}

To begin developing software and testing algorithms for faster feedback systems, hardware was installed in two locations of the accelerator. One system provided energy and position feedback for the beam leaving the Injector. The second system provided energy and position feedback for the beam after the first pass through the first linac. Each system consisted of a single VME crate housing an MVME167 CPU, a DAC for driving the actuators, and the specialized modules used for the SEEs.

Energy corrections to the beam were made using pairs of the installed SRF cavities. The VME DAC was used to drive a vernier input on the $R F$ control module. The distances between the DAC and the RF control module exceeded 800 feet in some places and special filters had to be added to reduce higher frequency transmission noise.

Position corrections to the beam were made using aircore corrector dipoles powered by a modified version of the standard CEBAF trim supply. The magnets were a pair of simple saddle coils designed to wrap around the existing vacuum pipe in the areas of interest. The magnets had a design strength of $750 \mathrm{G}-\mathrm{cm}$ in order to provide the corrections needed for a maximum beam energy of $845 \mathrm{MeV}$. The trim supplies were modified to accept and external voltage input. This input was driven by the VME DAC. Tests on this setup showed the load had an impedance of $3.85 \Omega+2 \pi f(7.4 \mathrm{mH})$ [5]. The trim supply voltage limit of 60 volts was able to compensate for the impedance changes for frequencies up to $500 \mathrm{~Hz}$. This setup provided an inexpensive method for orbit 
correction, made use of available hardware, and provided an acceptable bandwidth.

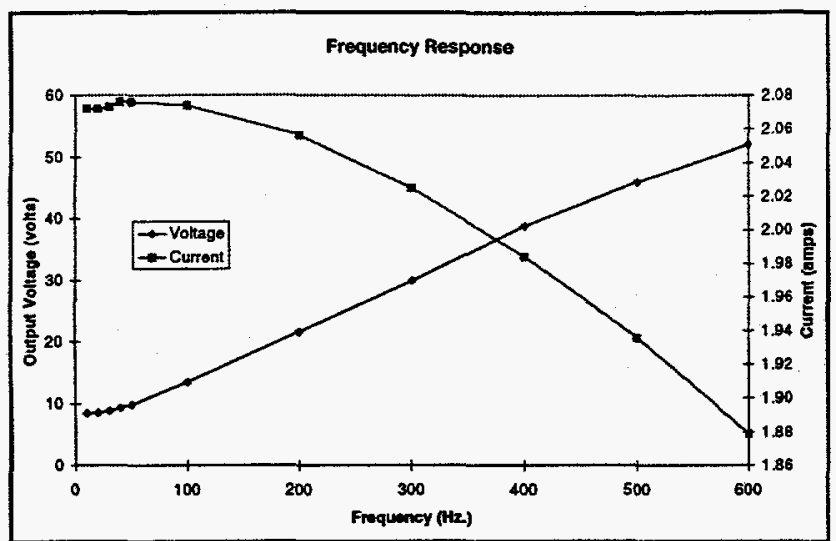

Figure 4: Trim Power Supply and Air-core corrector frequency response at 2 amps.

The SEE BPMs resided in locations from zero to high dispersion. The state matrix $\left(x, x^{\prime}, y, y^{\prime}\right.$, and $\left.\Delta E / E\right)$ could then be calculated using the known $M_{12}$ s of the transport matrix. The corrections were calculated using a state space modeling and the required signal sent to the actuators. Early tests performed with beam have been successfully made at an SEE BPM acquisition rate of 60 $\mathrm{Hz}$.

The optics for two of the experimental hall transport lines were changed to improve the sensitivity of feedback systems. The new optics increased the beta functions and dispersion by a factor of two. The betatron phase advance was also increased to $\pi / 2+\mathbf{n} \pi$ between actuators and monitors. This optics change achieved 2 to 3 times better resolution in comparison with the original optics.

\section{FUTURE WORK}

Future development includes making the tools used for measuring beam noise into a user friendly package.
Such a tool would provide operators a diagnostic for identifying and locating sources of beam instabilities. In past tests on the prototype feedback systems, the acquisition rate limit of $60 \mathrm{~Hz}$. was set by the SEE low level software. Upgrades to this software will eventually allow them to be read at up to $1 \mathrm{kHz}$. Also being investigated is the use of feed-forward to suppress the power line harmonics [4].

\section{CONCLUSIONS}

With low frequency disturbances on the beam under control the development of faster feedback systems has begun. Measurements made using multiple techniques show the main source of position and energy variations are at the power line harmonics of 60,120 , and $180 \mathrm{~Hz}$. Hardware has been installed in two locations to begin prototyping the feedback systems needed to suppress the observed disturbances. Both setups have been successfully operated at acquisition rates of $60 \mathrm{~Hz}$. Future work involves running these systems at the higher rates needed to achieve the CEBAF ultimate design goals.

\section{ACKNOWLEDGMENTS}

This work was supported by the U.S. DOE under contract number DE-AC05-84ER40150.

\section{REFERENCES}

[1] J. K. Ousterhout, TCl and the Tk Toolkit, AddisonWesley Professional Computing Series (1994)

[2] J. van Zeijts et al., Design and Implementation of a General Slow Orbit Control Package at Jefferson $L a b$, these proceedings.

[3] Matlab Reference Manual, Copyright The Math Works, Inc., 1984-1993.

[4] V. Lebedev, Feedback System for Energy and Beam Position Stabilization, Jefferson Lab Memo, 1996.

[5] R. Legg, et al., Fast Feedback Corrector System, Jefferson Lab Tech Note \#96-005, 1996. 